Revista Baiana de Saúde Pública
ARTIGO ORIGINAL DE TEMA LIVRE

\section{INCIDÊNCIA E DISTRIBUIÇÃO DA SÍFILIS CONGÊNITA NA BAHIA, 2005-2012}

\author{
Cristiana de Souza Meira Brasileiro ${ }^{a}$ \\ Guilherme de Sousa Ribeiro ${ }^{b}$
}

\begin{abstract}
Resumo
Embora a sífilis congênita (SC) possa ser prevenida por ações realizadas no pré-natal, ela ainda apresenta elevada incidência em diversas partes do mundo. Este estudo teve o objetivo de analisar aspectos epidemiológicos da SC na Bahia e em seus municípios, no período de 2005 a 2012. Foi realizado um estudo ecológico, de distribuição temporal e espacial, com caráter descritivo. Com base nos registros do Sistema de Informação de Agravos de Notificação e do Sistema de Informação sobre Mortalidade, foram identificados 2.656 casos de SC na Bahia no período. A incidência da SC no estado cresceu de 1,2 para 2,7 casos por 1.000 nascidos vivos (NV) entre 2005 e 2012. Comparando-se os quadriênios 2005-2008 e 2009-2012, observou-se redução no percentual dos municípios que apresentavam incidência da SC inferior à meta definida pela Organização Pan-americana da Saúde (até 0,5 caso por 1.000 NV) de 74,6\% para $63,1 \%$. Nesse último quadriênio, altas incidências médias anuais foram detectadas nas Regiões Leste, Sudoeste, Sul e Extremo Sul do estado. Concluiu-se que a crescente dispersão da SC na Bahia reforça a necessidade de ampliar os investimentos na vigilância e no controle da doença.
\end{abstract}

Palavras-chave: Sífilis congênita. Epidemiologia. Incidência.

INCIDENCE AND DISTRIBUTION OF CONGENITAL SYPHILIS IN BAHIA, 2005-2012

\begin{abstract}
Although actions taken during prenatal care may prevent congenital syphilis (CS), it continues to have high incidence in many parts of the world. This study aimed to analyze the epidemiological aspects of CS in Bahia and its municipalities, between 2005 and 2012. We performed a descriptive ecological study with temporal and spatial distribution. Based on Sinan

a Instituto de Saúde Coletiva. Universidade Federal da Bahia. Salvador, Bahia, Brasil.

b Instituto de Saúde Coletiva, Universidade Federal da Bahia. Centro de Pesquisas Gonçalo Moniz, Fundação Oswaldo Cruz. Salvador, Bahia, Brasil.

Endereço para correspondência: Rua Alexandrina Ramalho, número 157, apartamento 604, Candeal. Salvador, Bahia, Brasil. CEP: 40296-230. E-mail: csmeira@hotmail.com
\end{abstract}


and SIM records, we identified 2.656 cases of CS in Bahia within the period. The incidence of CS in the state increased from 1.2 to 2.7 cases per 1.000 live births (LB) between 2005 and 2012. Comparing the four-year periods 2005-2008 and 2009-2012, we observed a decrease from $74.6 \%$ to $63.1 \%$ of municipalities that reached a CS incidence bellow the target set by PAHO (less than 0.5 cases per 1.000 LB). In these last four years, high annual average incidences were found in the eastern, southwestern, southern and extreme south regions of the state. The increasing dispersal of CS in Bahia reinforces the need to augment investments in surveillance and disease control.

Keywords: Congenital syphilis. Epidemiology. Incidence.

INCIDENCIA Y DISTRIBUCIÓN DE SÍFILIS CONGÉNITA EN BAHÍA, 2005-2012

\section{Resumen}

Aun que la sífilis congénita (CS) se puede prevenir mediante acciones tomadas en la atención prenatal, ella ainda presenta alta incidencia en muchas partes del mundo. Este estudio tuvo como objetivo analizar los aspectos epidemiológicos de SC en Bahía y sus municipios en el período desde 2005 hasta 2012. Fue realizado un estudio ecológico de distribución temporal y espacial, con carácter descriptivo. Basándose en registros del Sinan y del SIM se identificaron 2.656 casos de SC en Bahía en el período. La incidencia de SC en el estado aumentó de 1,2 a 2,7 casos por 1.000 nacidos vivos (NV) entre 2005 y 2012. Comparandose los períodos de cuatro años desde 2005 hasta 2008 y desde 2009 hasta 2012, se observó una reducción en el porcentaje de municipios que mostraron incidencia de SC inferior a la meta establecida por la OPS (a 0,5 casos por cada 1.000 nacidos vivos) de 74,6\% a 63,1\%. En los últimos cuatro años, altas incidencias medias anuales fueron encontrados en la región del Éste, en el Suroeste, Sur y extremo Sur del estado. Se concluyó que la creciente dispersión de SC en Bahía refuerza la necesidad de aumentar las inversiones en vigilancia y control de enfermedades.

Palabras clave: Sífilis congénita. Epidemiología. Incidencia.

\section{INTRODUÇÃO}

A sífilis congênita (SC) é uma doença infecciosa de transmissão materno-fetal causada pelo Treponema pallidum. A infecção congênita pode resultar em malformação em múltiplos órgãos, bem como em morte fetal ou neonatal'. A SC pode ser evitada por meio de 
Revista Baiana de Saúde Pública assistência pré-natal qualificada, que garanta a identificação da infecção materna durante a gestação, e do tratamento com penicilina, cuja eficácia é em torno de 95 a 100\%². O início precoce do acompanhamento pré-natal é um componente essencial da prevenção, por viabilizar a detecção da sífilis materna e o tratamento oportunamente.

A despeito de ser uma infecção neonatal evitável, a SC ainda apresenta elevada incidência em diversos países ${ }^{3}$. A Organização Mundial de Saúde (OMS) estima que a cada ano dois milhões de gestantes sejam infectadas pelo Treponema pallidum no mundo. Dessas gestações, 25\% resultam em abortos espontâneos ou natimortos e outros 25\% em recém-nascidos com baixo peso ou infecção grave, com risco aumentado de morte perinatal ${ }^{3}$. Mundialmente, ocorrem cerca de 440.000 mortes perinatais decorrentes de SC por ano ${ }^{4}$.

Em 1995, a Organização Pan-americana da Saúde (OPAS) definiu como meta para os países das Américas a redução da incidência da SC para menos de 0,5 caso (incluindo natimortos) por 1.000 nascidos vivos (NV), com o objetivo de eliminar o problema de saúde pública que a doença representa nessa região ${ }^{5}$.

Apesar de os programas de controle da SC nos países das Américas terem adotado a meta proposta pela OPAS, a sífilis continua representando um problema de saúde pública na região ${ }^{6}$. Anualmente, entre 164 e 344 mil bebês nascem com SC nos continentes americanos ${ }^{6}$. Em 2009, os países da região que apresentavam as maiores incidências de SC eram o Uruguai (5,3 casos por $1.000 \mathrm{NV})$, o Paraguai (2,5 casos por $1.000 \mathrm{NV})$ e a Colômbia (2,2 casos por $1.000 \mathrm{NV})^{6}$. Em contrapartida, países como Chile, Cuba e Estados Unidos haviam atingido níveis de incidência compatíveis com a eliminação dessa doença como problema de saúde pública ${ }^{6}$.

No Brasil, estudos realizados em 2000 e 2006 identificaram uma prevalência de sífilis em parturientes de 1,7\% e 1,1\%, respectivamente, sugerindo que ocorram entre 32.000 e 49.000 infecções por sífilis em gestantes a cada ano no país ${ }^{7-8}$. Entretanto, a média anual de notificações de gestantes com sífilis no sistema nacional de informação - Sistema de Informação de Agravos de Notificação (Sinan) - foi de 11.000 casos no período de 2009 a $2011^{9}$. A média anual de casos de SC notificados, no mesmo período, foi de aproximadamente $7.500 \operatorname{casos}^{9}$. Evidências sugerem que a incidência de SC vem aumentando em diversos estados do Brasil e no país alcançou 3,3 casos por $1.000 \mathrm{NV}$ em 20119-12. No mesmo ano, o coeficiente de mortalidade por SC foi 3,8 óbitos por $100.000 \mathrm{NV}^{9}$.

No único estudo publicado sobre a epidemiologia da SC na Bahia, observaram-se incidências elevadas da doença em Salvador, variando de 1,3 a 3,1 casos por 1.000 NV, entre os anos de 1997 e $2002^{13}$. Dados mais recentes, produzidos pela Secretaria da Saúde 
do Estado da Bahia (Sesab), indicam que o número de notificações de SC na Bahia quase triplicou entre 2007 e 2012, elevando-se de 234 para 652 casos $^{14}$. A fim de nortear as ações de vigilância e controle da SC no estado, este estudo teve o objetivo de analisar aspectos epidemiológicos da SC na Bahia e em seus municípios, no período entre 2005 e 2012. Buscou-se estimar a incidência e a letalidade da SC no estado para cada ano do período de estudo e analisar a distribuição espacial da doença nos municípios baianos em dois quadriênios: 2005-2008 e 2009-2012.

\section{METODOLOGIA}

Foi realizado um estudo ecológico, de distribuição temporal e espacial, com caráter descritivo. A população do estudo foi composta pelos casos de SC, de acordo com a definição de caso do Ministério da Saúde (MS)c , ocorridos em crianças menores de um ano de idade, residentes na Bahia, no período 2005 a 2012.

O estado da Bahia tem 417 municípios distribuídos em área territorial de aproximadamente 565 mil km². Em 2010, a população do estado era 14.016.906 habitantes e a densidade demográfica 24,82 habitantes por $\mathrm{km}^{2}$. Os municípios da Bahia apresentam grande variação na área territorial $(32,2$ a 16.303,86 km²), no tamanho da população $(2.612$ a 2.675.656 habitantes) e na densidade populacional $\left(0,9 \text { a 3.859,40 habitantes por } \mathrm{km}^{2}\right)^{15}$.

Utilizaram-se as bases de dados do Sinan e do Sistema de Informação sobre Mortalidade (SIM), para melhor computar o número de casos de SC no estado da Bahia durante o período de estudo. Da base do Sinan foram incluídos os casos de SC em menores de 1 ano de idade. Da base de dados do SIM foram incluídos os óbitos fetais e os óbitos não fetais por SC, também em menores de 1 ano de idade. O código A50.9 (sífilis congênita não especificada) da 10 a Classificação Internacional de Doenças (CID 10) foi utilizado para identificar os casos de SC no Sinan e os óbitos por SC como causa básica no SIM. A base de dados do Sistema de Informação sobre Nascidos Vivos (Sinasc) foi utilizada para obtenção

\footnotetext{
Para fins de vigilância epidemiológica, a Secretaria de Vigilância em Saúde do MS define quatro critérios que compõem a definição de caso de SC. Primeiro critério: toda criança, ou aborto, ou natimorto de mãe com evidência clínica para sífilis e/ou com sorologia não treponêmica reagente para sífilis com qualquer titulação, na ausência de teste confirmatório treponêmico realizado no pré-natal ou no momento do parto ou curetagem, que não tenha sido tratada ou tenha recebido tratamento inadequado. Segundo critério: todo indivíduo com menos de 13 anos de idade com pelo menos uma das seguintes evidências sorológicas: titulações ascendentes (em testes não treponêmicos) ou testes não treponêmicos reagentes após seis meses de idade (exceto em situação de seguimento terapêutico); ou testes treponêmicos reagentes após 18 meses de idade; ou títulos em teste não treponêmico maiores do que os da mãe. Terceiro critério: todo indivíduo com menos de 13 anos, com teste não treponêmico reagente e evidência clínica, liquórica ou radiológica de sífilis congênita. Quarto critério: toda situação de evidência de infecção pelo T. pallidum na placenta, no cordão umbilical ou em amostras da lesão, biopsia ou necropsia de criança, produto de aborto ou natimorto, por meio de exames microbiológicos.
} 
Revista Baiana de Saúde Pública do número de nascidos vivos na Bahia e em seus municípios durante cada ano do período de estudo.

Utilizou-se a metodologia de relacionamento das bases de dados para integrar as duas bases existentes do Sinan (uma denominada versão Windows, usada entre 2000 e 2006; e outra denominada versão Net, em uso desde 2007) e a base de dados do SIM. Após relacionar as três bases de dados, foram excluídas as duplicidades de registros identificadas visualmente com base na semelhança nos dados presentes para as seguintes variáveis: nome do paciente notificado como caso ou óbito por SC, nome da mãe do paciente e data de nascimento do paciente. Também foram consideradas, para confirmar ou descartar os registros suspeitos de duplicidade, as variáveis bairro de residência, endereço de residência e município de residência do paciente. Em caso de identificação de registros duplicados, foram considerados os seguintes critérios para definir qual dos registros seria mantido para as análises: nas duplicidades existentes em um mesmo sistema, manteve-se a primeira notificação, conforme orientação do manual do Sinan ${ }^{16}$; nas duplicidades identificadas no Sinan e no SIM, manteve-se o registro notificado no Sinan, por ser esse o sistema oficial de notificação de doenças. Como fazia parte dos critérios de inclusão de caso deste estudo ter idade inferior a 1 ano, foram excluídos os registros nos quais não havia dados sobre idade e data de nascimento dos pacientes. No entanto, optou-se por incluir os casos sem dados sobre idade e data de nascimento, mas nos quais constassem as palavras recém-nascido, natimorto ou feto morto, ou ainda as siglas RN (recém-nascido) ou NM (natimorto), uma vez que elas são indicativas de que a doença foi detectada ao nascimento ou precocemente após o nascimento. A comparação entre as bases de dados foi realizada por meio do programa Excel (Microsoft Office 2010).

A ocorrência de SC foi analisada segundo o ano calendário e o município de residência dos casos. Calcularam-se os coeficientes anuais de incidência de SC da Bahia por meio da razão entre o número de casos novos de SC registrados no Sinan e no SIM (excluídos os registros em duplicidade) a cada ano e a população de nascidos vivos nos respectivos anos. Esse indicador foi expresso por 1.000 NV. Incidências médias anuais para os quadriênios 2005 a 2008 e 2009 a 2012 foram calculadas para o estado, bem como para cada município, pela razão entre a soma dos casos de SC registrados no Sinan e no SIM em cada um dos quadriênios e a soma da população de NV nos mesmos períodos. Para os municípios com incidência média anual diferente de zero no primeiro quadriênio, calculou-se a proporção da variação da incidência entre os quadriênios 2005-2008 e 2009-2012.

A incidência média anual de SC estimada para os 417 municípios, nos dois quadriênios (2005-2008 e 2009-2012), foi estratificada de forma a classificar os municípios 
da Bahia em seis níveis de risco e ocorrência da SC: (1) incidência média anual igual a 0 caso por $1.000 \mathrm{NV}$; (2) de 0,01 a 0,50 caso por $1.000 \mathrm{NV}$ (faixa que corresponde aos municípios com registros de casos e cujas incidências situavam-se dentro da meta estabelecida pela OPAS, de menos de 0,5 caso por $1.000 \mathrm{NV}$ ); (3) de 0,51 a 1,00 caso por $1.000 \mathrm{NV}$ (até 2 vezes acima de meta); (4) de 1,01 a 2,50 casos por $1.000 \mathrm{NV}$ (de 2 a 5 vezes acima de meta); (5) de 2,51 a 5,00 casos por 1.000 NV (5 a 10 vezes acima da meta); e (6) acima de 5,01 casos por 1.000 NV (mais de 10 vezes acima da meta). Essa categorização foi adotada para minimizar a grande variação das incidências anuais médias entre os municípios e por expressar o nível de incidência da SC nos municípios da Bahia em relação à meta de controle da doença estabelecida pela OPAS. A distribuição espacial da incidência média anual da SC (estratificada nos seis níveis previamente referidos) nos dois quadriênios foi projetada em mapas da Bahia segundo municípios. A base cartográfica digital utilizada foi obtida na página eletrônica do Departamento de Informática do SUS (Datasus), do Ministério da Saúde.

Calcularam-se as letalidades por SC dos anos 2005 a 2012 por meio da razão entre o número de óbitos por SC registrados no estado a cada ano e o número de casos de SC registrados no mesmo ano.

O projeto desta pesquisa foi aprovado pelo Comitê de Ética em Pesquisa do Instituto de Saúde Coletiva da Universidade Federal da Bahia (Parecer n. 791.843). Por se tratar de estudo realizado com dados secundários, o Comitê de Ética em Pesquisa isentou os pesquisadores da necessidade de solicitar o Consentimento Livre e Esclarecido.

\section{RESULTADOS}

Entre 2005 e 2012, foram registrados 584 casos de SC no Sinan Windows (versão antiga, usada até 2006), 2.132 casos de SC no Sinan Net 4.0 (versão em uso desde 2007) e 46 óbitos por SC no SIM, a perfazer o total inicial de 2.762 casos de SC registrados na Bahia no período. As análises de duplicidade de registros identificaram 100 pares de duplicidades, dos quais 79 eram pares de registros duplicados no Sinan e 21 eram pares de registros duplicados entre o Sinan e o SIM. Após exclusão dos registros duplicados e dos casos sem informação sobre idade (3 registros) ou com idade maior de 1 ano (3 registros), o número final de casos de SC incluídos no estudo foi 2.656 (Figura 1). 
Revista Baiana de Saúde Pública
Figura 1 - Relacionamento das bases de dados de SC do Sistema de Informação de Agravos de Notificação, versão Windows e versão Net, e do Sistema de Informação sobre Mortalidade. Estado da Bahia, 2005-2012

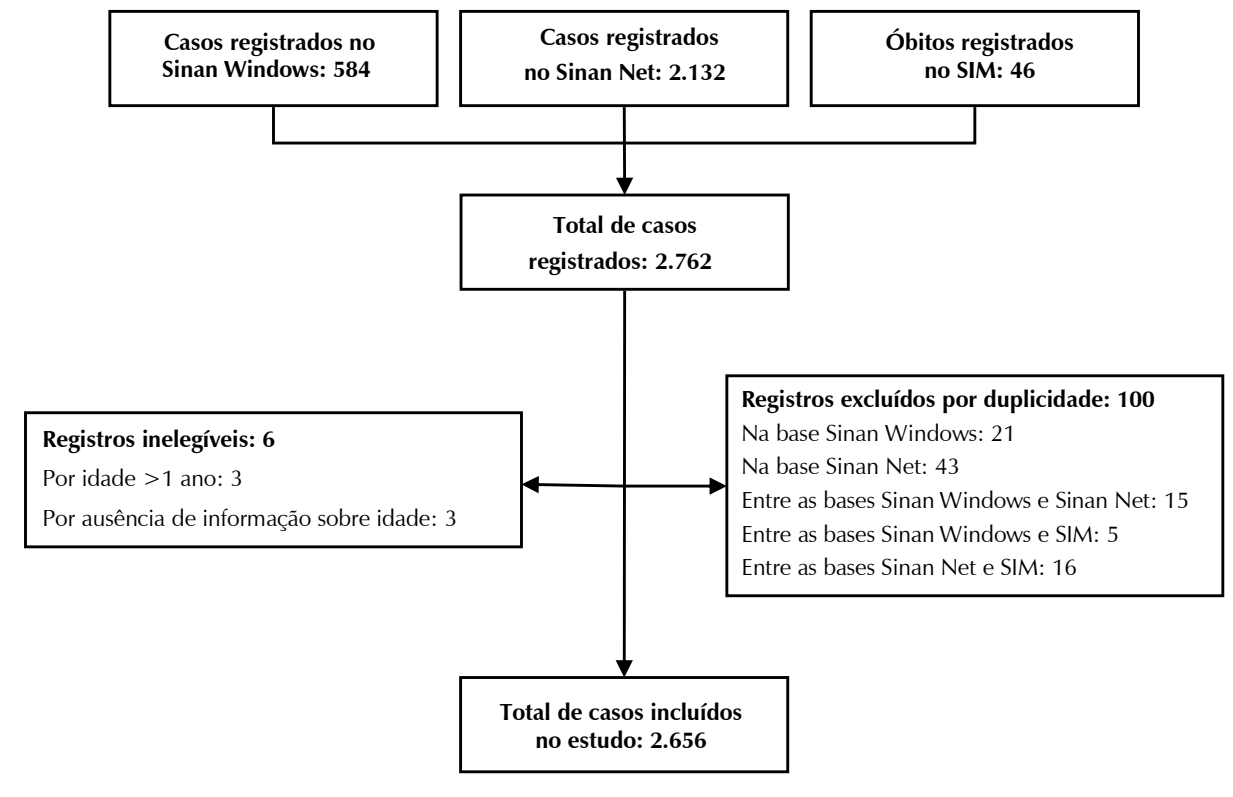

Fonte: Elaboração própria.

Entre 2005 e 2012, a incidência da SC em menores de 1 ano aumentou de 1,2 para 2,7 casos por $1.000 \mathrm{NV}$ na Bahia, o que representa o incremento acumulado de $125 \%$ e crescimento médio anual de 13,6\% (Gráfico 1). Entretanto, o crescimento dessa incidência não ocorreu de forma linear; houve discreta redução de 2005 a 2008 (de 1,2 para 1,0 caso por 1.000 NV), seguido de um aumento linear desse coeficiente a partir desse ano. Considerando apenas o período entre 2008 e 2012, observou-se um aumento de 170\% na incidência de SC em menores de 1 ano na Bahia. 
Gráfico 1 - Incidência de sífilis congênita em menores de 1 ano de idade (por $1.000 \mathrm{NV}$ ), segundo o ano do diagnóstico. Estado da Bahia, 2005-2012

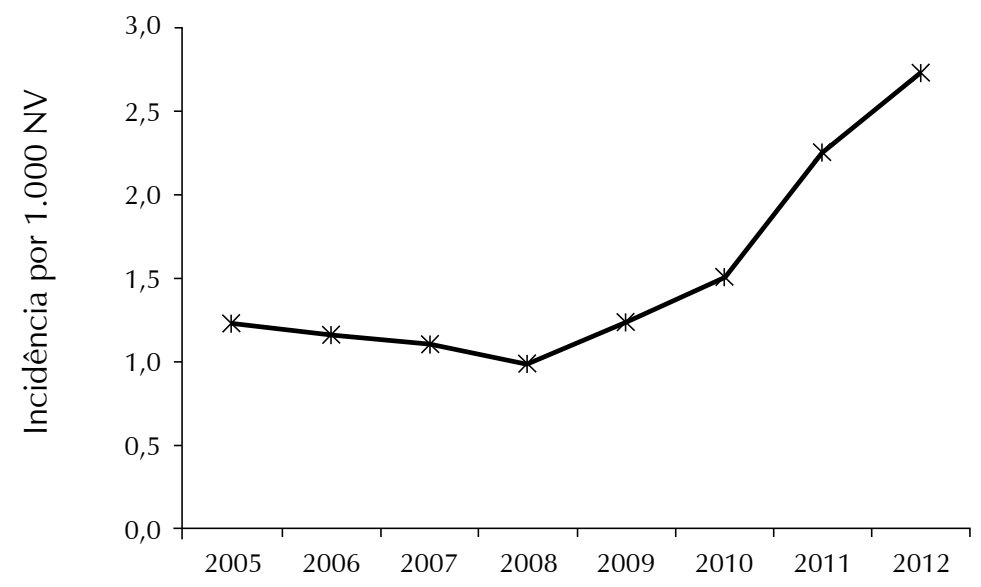

Fonte: Elaboração própria com base em dados coletados do Sinan Windows, Sinan NET, SIM e Sinasc.

O aumento observado na incidência média anual de SC em menores de 1 ano não ocorreu de forma homogênea em todos os 417 municípios do estado. Dentre os 417 municípios baianos, 129 (30,9\%) registraram casos de SC no período entre 2005 e 2008 e 171 $(41,0 \%)$ registraram casos no período entre 2009 e 2012. Dos 129 municípios com incidência diferente de zero no primeiro quadriênio, houve redução da incidência média anual em 69 (53,5\%) deles e aumento em 60 (46,5\%). Digno de nota, em 25 (19,4\%) desses 129 municípios, o aumento foi superior ou igual a 100\%. Destaca-se que em 5 municípios (Ilhéus, Itabela, Jequié, Rio Real e Sento Sé) a variação percentual foi superior a 500\% (Apêndice A).

A Figura 2 mostra a distribuição das incidências médias anuais dos municípios da Bahia, nos períodos 2005-2008 e 2009-2012. Observa-se, no primeiro quadriênio, que 311 $(74,6 \%)$ municípios alcançaram a meta estabelecida pela OPAS de incidência menor ou igual a 0,5 caso por $1.000 \mathrm{NV}$; enquanto 106 (25,4\%) municípios apresentaram incidências médias superiores a 0,5 caso por $1.000 \mathrm{NV}$ e dentre esses a maioria $(57,5 \%)$ apresentava incidência média anual entre 1,01 a 2,50 casos por $1.000 \mathrm{NV}$ (de 2 a 5 vezes acima da meta). Nesse período, apenas Porto Seguro apresentou incidência acima de 5,01 casos por $1.000 \mathrm{NV}$ (mais de 10 vezes acima da meta).

No segundo quadriênio analisado, houve redução do percentual dos que alcançaram a meta para 63,1\% (263 municípios). Dos 154 (36,9\%) municípios que apresentam incidência acima da meta, a maioria $(45,4 \%)$ também apresentava incidência média anual entre 
Revista Baiana de Saúde Pública

1,01 e 2,50 casos por 1.000 NV (de 2 a 5 vezes acima da meta). No entanto, destaca-se que 44 municípios (28,6\%) tiveram incidência maior que 2,51 casos por $1.000 \mathrm{NV}$ (mais de 5 vezes acima da meta) e 8 desses com incidência maior que 5,1 casos por $1.000 \mathrm{NV}$ (mais de 10 vezes acima da meta). As maiores incidências médias anuais foram registradas nos municípios: Contendas do Sincorá (10,20 casos por 1.000 NV), Ilhéus (8,39 casos por 1.000 NV) e Teixeira de Freitas (7,77 casos por 1.000 NV). Com exceção de 2010, Contendas do Sincorá mostrou-se silencioso em todos os anos do período do estudo (2005-2012), no entanto, apresentou a incidência média anual mais elevada do estado no período 2009-2012 devido à ocorrência de 2 casos em 2010. Já Porto Seguro reduziu a sua incidência média anual em 53,1\% nesse segundo quadriênio (de 8,81 para 4,13 casos por 1.000 NV) (Figura 2).

No período de 2005 a 2008, observou-se agregação espacial de municípios com incidências médias anuais de SC mais elevadas (acima de 2,5 caso por $1.000 \mathrm{NV}$ ) nas Regiões Centro-Leste e Sul do estado. Já no quadriênio seguinte (2009-2012), a dispersão dos municípios com incidências mais elevadas é maior e as regiões que concentraram as incidências mais elevadas foram Leste, Sul, Extremo Sul e Sudoeste (Figura 2).

Figura 2 - Incidência média anual de SC em menores de 1 ano de idade (por 1.000 NV), segundo município de residência. Estado da Bahia, 2005-2008 (A) e 2009-2012 (B)

A

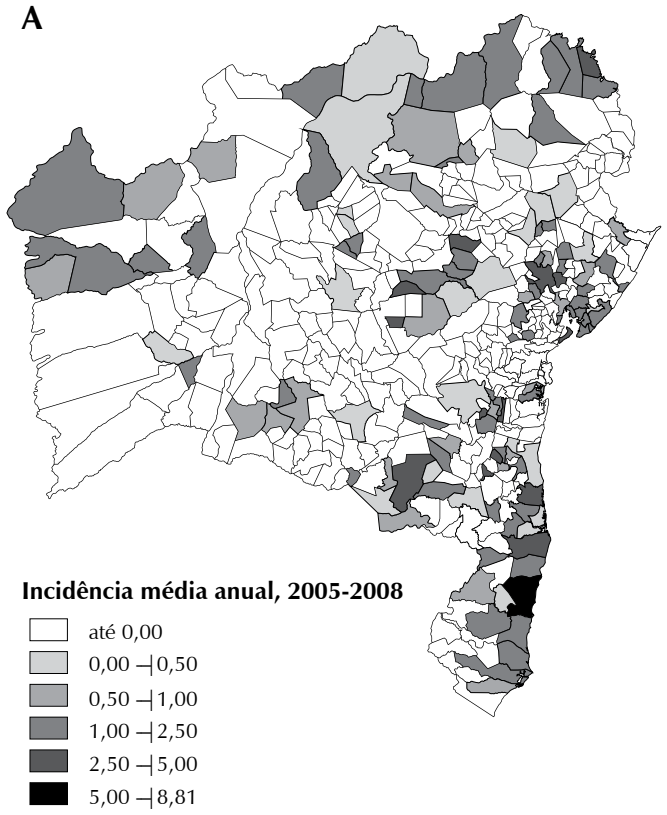

B

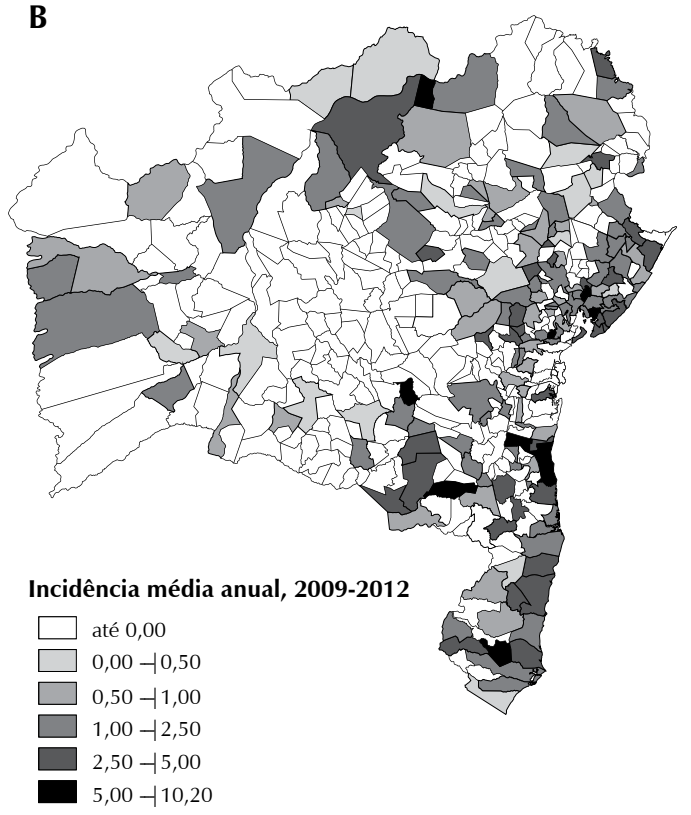

Fonte: Elaboração própria com base em dados coletados no Sinan Windows, Sinan NET, SIM e Sinasc. 
No período de 2005 a 2012, foram identificados 197 óbitos por SC elegíveis para esta pesquisa. Dentre esses, 42 estavam registrados no SIM e 155 no Sinan, os últimos representados pelos casos de SC classificados como aborto, natimorto, óbito fetal ou óbito por SC. Observou-se que 17 registros eram comuns às duas bases, o que resultou em uma amostra final de 180 óbitos por SC registrados nesse período. A letalidade por SC na Bahia mostrou-se em declínio no período do estudo; em 2005 foi de 13,6\% e reduziu para 5,7\% em 2012, o que representou uma redução de 58\% (Gráfico 2).

Gráfico 2 - Letalidade por sífilis congênita segundo o ano. Estado da Bahia, 2005-

2012

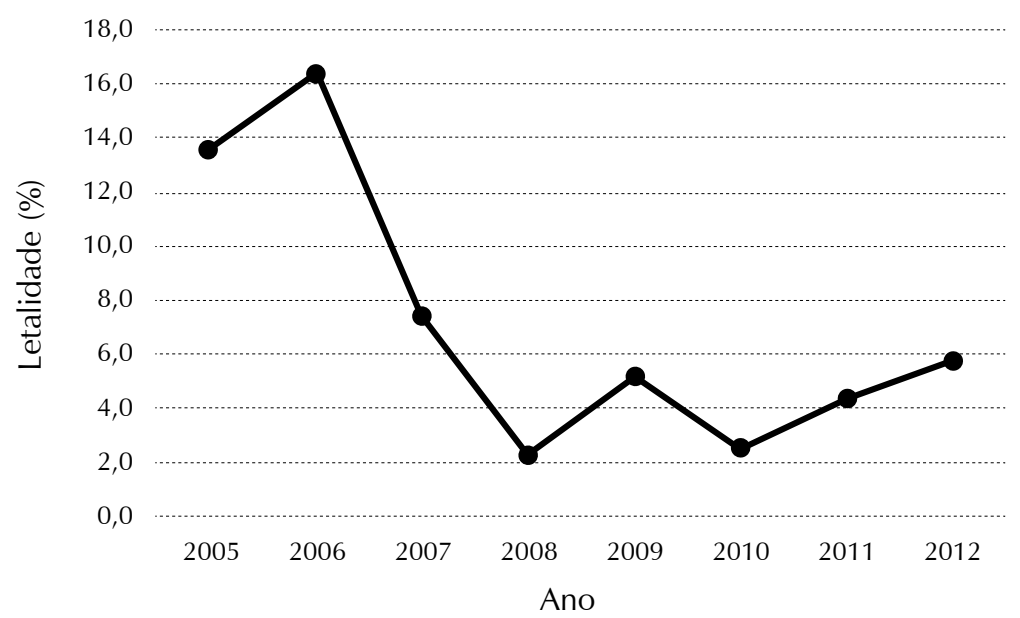

Fonte: Elaboração própria com base em dados coletados do Sinan Windows e Sinan NET e SIM.

\section{DISCUSSÃO}

Os achados deste estudo demonstram que, apesar dos esforços para prevenção e controle da SC, ela permanece como um importante problema de saúde pública em diversos municípios do estado da Bahia. A SC é uma doença que pode ser prevenida com a detecção oportuna e tratamento adequado de mulheres em idade fértil e gestantes com sífilis. A elevada incidência de SC observada sugere que haja transmissão sexual da sífilis no estado. Além disso, revela a fragilidade da assistência pré-natal e da rede de atenção à saúde na Bahia. A ocorrência de tão somente um caso em uma localidade sinaliza a falta de efetividade da atenção pré-natal' .

A tendência ascendente da incidência de SC na Bahia também foi observada no Ceará, entre 2000 e 2009 (de 0,1 a 4,9 por 1.000 NV) ${ }^{10}$ e em Belo Horizonte, de 2001 a 2008 (de 0,9 a 1,6 por 1.000 NV) ${ }^{11}$. No Mato Grosso e na capital desse estado, Cuiabá, no período 
Revista Baiana de Saúde Pública de 2001 a 2009, constatou-se que a tendência de crescimento da incidência de SC não foi estatisticamente significante, variando de 0,4 a 1,7 casos por $1.000 \mathrm{NV}$ e de 0,6 a 4,1 casos por $1.000 \mathrm{NV}$, respectivamente ${ }^{12}$. Já no Rio Grande do Norte, observou-se aumento, seguido de redução da incidência de SC entre 2007 e 2010, variando de 2,7 casos por 1.000 NV em 2007 a 0,9 casos por 1.000 NV em 2010, mas com picos nos anos 2008 e 2009 de 4,3 casos por $1.000 \mathrm{NV}^{17}$. A pequena série temporal deste estudo não permite apontar com clareza a existência de uma tendência de ascensão ou decréscimo na incidência de SC no estado do Rio Grande do Norte.

Em estudo sobre SC realizado em Salvador, no período entre 1997 e 2002, também se observou uma oscilação na incidência da SC (mínimo de 1,3 e máximo de 3,1 casos por $1.000 \mathrm{NV}$ ) que não caracterizava uma tendência clara sobre a incidência da $\mathrm{SC}^{13}$. Entretanto, nossa observação de que a incidência média anual da SC em Salvador nos períodos 2005-2008 e 2009-2012 foram de aproximadamente 2,5 e 4,1 casos por $1.000 \mathrm{NV}$, sugere a tendência de aumento na capital da Bahia. Ainda em Salvador, um estudo estimou a soroprevalência de sífilis em uma amostra representativa de parturientes da capital em 0,51\%, no período de 2008 a $2009^{18}$. Esta prevalência foi inferior à observada na região nordeste em 2006, de 0,8\% ${ }^{9}$. Em contrapartida, a prevalência de sífilis em amostra de gestantes HIV positivas, assistidas em Serviço de Assistência Especializada (SAE) de referência no estado da Bahia, foi de 9,5\% ${ }^{19}$.

A interpretação de resultados de estudos realizados com dados secundários, oriundos dos sistemas de informação do SUS, demanda cautela em função de municípios e unidades federadas brasileiras apresentarem diferentes estágios de implantação, desenvolvimento e organização desses sistemas, com consideráveis variações de cobertura e disponibilidade de dados ${ }^{20}$. É possível que parte das diferenças entre as incidências de SC nos municípios da Bahia seja devido a diferenças na qualidade do sistema de vigilância epidemiológica desses territórios. Nesse contexto, a identificação de municípios sem qualquer registro de casos de SC nos quadriênios estudados merece uma cuidadosa avaliação. Diante do acelerado crescimento da incidência de SC no estado, é pertinente supor que parte desses municípios esteja silenciosa devido a mau funcionamento nos registros das informações da vigilância epidemiológica. Por outro lado, é possível que os municípios com as maiores incidências tenham um sistema de vigilância mais organizado e ativo. A possibilidade de sub-registro, em especial nos municípios com uma assistência pré-natal e um sistema de vigilância epidemiológica menos estruturado, faz supor que a incidência de SC na Bahia pode ser ainda maior que a estimada. Ainda é possível que parte do aumento da incidência da SC na Bahia deva-se à melhora dos sistemas locais de vigilância nos municípios do estado entre 2005 e 2012. 
Em relação à qualidade do registro dos óbitos por SC, foi observado que o número de óbitos registrados no SIM com a SC como causa básica foi cerca de quatro vezes menor que o número de óbitos por SC registrado no Sinan. Essa situação justifica-se em parte pela má qualidade do registro do óbito perinatal, como descrita em outros estudos $^{21-22}$. Entretanto, uma das limitações do presente estudo foi ter incluído somente os registros do SIM cuja causa básica era a SC, pois a SC pode ser causa contribuinte de óbitos em crianças menores de 1 ano. Um estudo realizado no estado do Amazonas, no período 2007 a 2009, que utilizou as bases de dados de sífilis em gestante, de SC no Sinan e de óbitos com causa relacionada à SC no SIM, revelou que a proporção de óbitos registrados no SIM que tinham a SC como causa adjacente e/ou associada era igual àquela que tinha a SC como causa básica ${ }^{21}$.

No presente estudo, não foi incluída a base de dados de sífilis em gestante do Sinan como uma das fontes para detecção de casos de SC. Embora esta seja uma limitação, uma vez que seria possível captar casos de SC com base nos casos de sífilis não tratados ou tratados inadequadamente na gestação, a sífilis em gestante só passou a ser um agravo de notificação compulsória a partir de 2006 e a inclusão das fichas de notificação e investigação no Sinan só ocorreu a partir de janeiro de $2007^{23}$. Portanto, a base de dados sobre sífilis em gestante não continha registros disponíveis para todo o período do estudo.

\section{CONSIDERAÇÕES FINAIS}

A incidência da SC na Bahia permanece acima da meta para sua eliminação como problema de saúde pública e as presentes evidências sugerem que a magnitude da ocorrência da doença no estado esteja aumentando. Futuros estudos são necessários para identificar os determinantes da SC na Bahia, bem como para avaliar a efetividade de estratégias para ampliar a cobertura no diagnóstico e tratamento da sífilis na gestação.

As discrepâncias encontradas nas incidências de SC entre os municípios da Bahia, em que uma parcela deles não apresenta registro da doença enquanto outra mostra elevada incidência da doença, alertam para a necessidade de se investir na ampliação da cobertura e na qualificação do cuidado pré-natal, a fim de promover a detecção e o tratamento oportuno da sífilis em gestantes.

\section{AGRADECIMENTOS}

Agradecemos à Secretaria da Saúde do Estado da Bahia (Sesab), sobretudo à Superintendência de Vigilância e Proteção à Saúde (Suvisa), e ao Instituto de Saúde Coletiva 
Revista Baiana de Saúde Pública da Universidade Federal da Bahia (ISC/UFBA), pela oferta do Mestrado Profissional em Saúde Coletiva, com ênfase em Epidemiologia em Serviços de Saúde. À Diretoria de Vigilância Epidemiológica (Divep/Suvisa/Sesab), um agradecimento especial, pela disponibilização das bases de dados e por todo o suporte oferecido para o desenvolvimento da pesquisa. Aos professores Juarez Pereira Dias e Licia Maria Oliveira Moreira, pelas contribuições para a elaboração deste artigo.

\section{COLABORADORES:}

Concepção do projeto, análise e interpretação dos dados: Cristiana de Souza Meira Brasileiro e Guilherme de Sousa Ribeiro.

2. Redação do artigo e revisão crítica relevante do conteúdo intelectual: Cristiana de Souza Meira Brasileiro e Guilherme de Sousa Ribeiro.

3. Revisão e/ou aprovação final da versão a ser publicada: Cristiana de Souza Meira Brasileiro.

4. Ser responsável por todos os aspectos do trabalho na garantia da exatidão e integridade de qualquer parte da obra: Cristiana de Souza Meira Brasileiro.

\section{REFERÊNCIAS}

1. Brasil. Ministério da Saúde. Secretaria de Vigilância em Saúde. Guia de vigilância epidemiológica. Brasília; 2005.

2. Alexander JM, Sheffield JS, Sanchez PJ, Mayfield J, Wendel Jr GD. Efficacy of treatment for syphilis in pregnancy. Obstet Gynecol. 1999;93(1):5-8.

3. Organização Mundial de Saúde. Eliminação mundial da sífilis congénita: fundamento lógico e estratégia para acção. Genebra; 2008.

4. Organização Mundial de Saúde. Methods for surveillance and monitoring of congenital syphilis elimination within existing systems. Geneva; 2011.

5. Organização Pan-Americana da Saúde. Plan of action for elimination of congenital syphilis. Washington (DC): PAHO; 1995.

6. Organização Pan-Americana da Saúde. 2010 Situation analysis: elimination of mother-to-child transmission of HIV and congenital syphilis. Washington (DC): PAHO; 2011.

7. Szwarcwald CL, Barbosa Junior A, Miranda AE, Paz LC. Resultados do estudo sentinela-parturiente, 2006: desafios para o controle da sífilis congênita no Brasil. J bras doenças sex transm. 2007;19(3-4):128-33. 
8. Rodrigues CS, Guimarães MDC. Grupo Nacional de Estudo sobre Sífilis Congênita. Positividade para sífilis em puérperas: ainda um desafio para o Brasil. Rev Panam Salud Publica. 2004;16(3):168-75.

9. Brasil. Ministério da Saúde. Boletim Epidemiológico - Sífilis. Brasília (DF); 2012.

10. Costa CC, Freitas LV, Sousa DMN, Oliveira LL, Chagas ACMA, Lopes MVO, et al. Sífilis congênita no Ceará: análise epidemiológica de uma década. Rev Esc Enferm USP. 2013;47(1):152-9.

11. Lima MG, Santos RFR, Barbosa GJA, Ribeiro GS. Incidência e fatores de risco para sífilis congênita em Belo Horizonte, Minas Gerais, 2001-2008. Ciênc Saúde Coletiva. 2013;18(2):499-506.

12. Oliveira LR, Costa MCN, Barreto FR, Pereira SM, Dourado I, Teixeira MG. Evaluation of preventative and control measures for congenital syphilis in State of Mato Grosso. Rev Soc Bras Med Tropical. 2014 May-Jun;47(3):334-40.

13. Almeida FMG, Pereira SM. Caracterização epidemiológica da sífilis congênita no município de Salvador, Bahia. DST - J Bras Doenças Sex Transm 2007;19(3-4):144-56.

14. Bahia. Secretaria da Saúde. Diretoria de Vigilância Epidemiológica. Programa Estadual de DST e Aids. Informe Epidemiológico Sífilis. Salvador; 2013.

15. Instituto Brasileiro de Geografia e Estatística. Homepage. Rio de Janeiro; 2014 [citado 2014 set 10]. Disponível em: http://www.ibge.org.br

16. Brasil. Ministério da Saúde. Secretaria de Vigilância em Saúde. Departamento de Vigilância Epidemiológica. Sistema de Informação de Agravos de Notificação - Sinan: normas e rotinas. 2a ed. Brasília (DF); 2007.

17. Carvalho IS, Brito RS. Sífilis congênita no Rio Grande do Norte: estudo descritivo do período 2007-2010. Epidemiol Serv Saúde. 2014 abr-jun;23(2):287-94.

18. Nóbrega I, Dantas P, Rocha P, Rios I, Abraão M, Martins Netto E, et al. Syphilis and HIV-1 among parturient women in Salvador, Brazil: low prevalence of syphilis and high rate of loss to follow-up in HIV-infected women. Brazil J Infect Dis. 2013;17(2):184-93.

19. Travassos AGA, Brites C, Martins Netto E, Fernandes SA, Rutherford GW, Queiroz CM. Prevalence of sexually transmitted infections among HIV-infected women in Brazil. Brazil J Infect Dis. 2012;16(6):581-5.

20. Costa MCN, Mota ELA, Paim JS, Silva LMV, Teixeira MG, Mendes CMC. Mortalidade infantil no Brasil em períodos recentes de crise econômica. Rev Saúde Pública. 2003;37(6):699-706. 
Revista Baiana de Saúde Pública
21. Soeiro CMO, Miranda AE, Saraceni V, Santos MC, Talhari S, Ferreira LCL. Syphilis in pregnancy and congenital syphilis in Amazonas State, Brazil: an evaluation using database linkage. Cad Saúde Pública. 2014 Apr;30(4):715-23.

22. Gonçalves VF, Kerr LRFS, Mota RMS, Mota JMA. Estimativa de subnotificação de casos de Aids em uma capital do Nordeste. Rev bras Epidemiol. 2008;11(3):356-64.

23. Saraceni V, Guimarães MHFS, Theme Filha MM, Leal MC. Mortalidade perinatal por sífilis congênita: indicador da qualidade da atenção à mulher e à criança. Cad Saúde Pública. 2005 jul-ago;21(4):1244-50.

Recebido: 16.7.2015. Aprovado: 29.8.2015. Publicado: 20.9.2017. 
APÊNDICE A - TABELA DE INCIDÊNCIA MÉDIA ANUAL DE SÍFILIS CONGÊNITA

EM MENORES DE 1 ANO DE IDADE (POR 1.000 NV) SEGUNDO MUNICÍPIO

DE RESIDÊNCIA. ESTADO DA BAHIA - 2005-2008 E 2009-2012

(continua)

\begin{tabular}{|c|c|c|c|c|c|}
\hline \multirow[b]{2}{*}{ Município de residência } & \multicolumn{2}{|c|}{ 2005-2008 } & \multicolumn{2}{|r|}{ 2009-2012 } & \multirow[b]{2}{*}{ Variação em \% } \\
\hline & no & $\begin{array}{c}\text { Incidência Média } \\
\text { Anual }\end{array}$ & no & $\begin{array}{c}\text { Incidência Média } \\
\text { Anual }\end{array}$ & \\
\hline Abaíra & 0 & 0,00 & 0 & 0,00 & \\
\hline Abaré & 0 & 0,00 & 0 & 0,00 & \\
\hline Acajutiba & 0 & 0,00 & 1 & 1,08 & \\
\hline Adustina & 0 & 0,00 & 0 & 0,00 & \\
\hline Água Fria & 1 & 1,30 & 0 & 0,00 & $-100,00$ \\
\hline Aiquara & 1 & 3,47 & 0 & 0,00 & $-100,00$ \\
\hline Alagoinhas & 8 & 0,94 & 11 & 1,25 & 33,35 \\
\hline Alcobaça & 2 & 1,28 & 4 & 3,13 & 145,45 \\
\hline Almadina & 1 & 2,67 & 0 & 0,00 & $-100,00$ \\
\hline Amargosa & 0 & 0,00 & 9 & 4,58 & \\
\hline Amélia Rodrigues & 2 & 1,39 & 3 & 2,21 & 58,72 \\
\hline América Dourada & 0 & 0,00 & 0 & 0,00 & \\
\hline Anagé & 0 & 0,00 & 3 & 2,91 & \\
\hline Andaraí & 0 & 0,00 & 0 & 0,00 & \\
\hline Andorinha & 0 & 0,00 & 0 & 0,00 & \\
\hline Angical & 1 & 1,38 & 0 & 0,00 & $-100,00$ \\
\hline Anguera & 0 & 0,00 & 0 & 0,00 & \\
\hline Antas & 0 & 0,00 & 0 & 0,00 & \\
\hline Antônio Cardoso & 1 & 1,36 & 0 & 0,00 & $-100,00$ \\
\hline Antônio Gonçalves & 1 & 1,64 & 3 & 5,58 & 239,03 \\
\hline Aporá & 0 & 0,00 & 2 & 2,24 & \\
\hline Apuarema & 1 & 2,20 & 0 & 0,00 & $-100,00$ \\
\hline Araçás & 0 & 0,00 & 3 & 4,24 & \\
\hline Aracatu & 0 & 0,00 & 0 & 0,00 & \\
\hline Araci & 1 & 0,31 & 4 & 1,27 & 309,41 \\
\hline Aramari & 0 & 0,00 & 0 & 0,00 & \\
\hline Arataca & 0 & 0,00 & 0 & 0,00 & \\
\hline Aratuípe & 0 & 0,00 & 1 & 2,22 & \\
\hline Aurelino Leal & 0 & 0,00 & 0 & 0,00 & \\
\hline
\end{tabular}


Revista Baiana de Saúde Pública
APÊNDICE A - TABELA DE INCIDÊNCIA MÉDIA ANUAL DE SÍFILIS CONGÊNITA

EM MENORES DE 1 ANO DE IDADE (POR 1.000 NV) SEGUNDO MUNICÍPIO

DE RESIDÊNCIA. ESTADO DA BAHIA - 2005-2008 E 2009-2012

(continuação)

\begin{tabular}{|c|c|c|c|c|c|}
\hline \multirow[b]{2}{*}{ Município de residência } & \multicolumn{2}{|r|}{ 2005-2008 } & \multicolumn{2}{|r|}{ 2009-2012 } & \multirow[b]{2}{*}{ Variação em \% } \\
\hline & no & $\begin{array}{c}\text { Incidência Média } \\
\text { Anual }\end{array}$ & no & $\begin{array}{c}\text { Incidência Média } \\
\text { Anual }\end{array}$ & \\
\hline Baianópolis & 0 & 0,00 & 0 & 0,00 & \\
\hline Baixa Grande & 2 & 1,43 & 2 & 1,96 & 36,69 \\
\hline Banzaê & 0 & 0,00 & 0 & 0,00 & \\
\hline Barra & 0 & 0,00 & 4 & 1,17 & \\
\hline Barra da Estiva & 0 & 0,00 & 0 & 0,00 & \\
\hline Barra do Choça & 1 & 0,38 & 0 & 0,00 & $-100,00$ \\
\hline Barra do Mendes & 0 & 0,00 & 0 & 0,00 & \\
\hline Barra do Rocha & 2 & 4,63 & 0 & 0,00 & $-100,00$ \\
\hline Barreiras & 12 & 1,23 & 9 & 0,86 & $-30,03$ \\
\hline Barro Alto & 1 & 1,19 & 0 & 0,00 & $-100,00$ \\
\hline Barro Preto & 0 & 0,00 & 0 & 0,00 & \\
\hline Barrocas & 1 & 1,64 & 1 & 1,14 & $-30,48$ \\
\hline Belmonte & 4 & 2,60 & 2 & 1,31 & $-49,51$ \\
\hline Belo Campo & 1 & 0,83 & 0 & 0,00 & $-100,00$ \\
\hline Biritinga & 0 & 0,00 & 0 & 0,00 & \\
\hline Boa Nova & 0 & 0,00 & 0 & 0,00 & \\
\hline Boa Vista do Tupim & 1 & 0,70 & 0 & 0,00 & $-100,00$ \\
\hline Bom Jesus da Lapa & 0 & 0,00 & 1 & 0,24 & \\
\hline Bom Jesus da Serra & 0 & 0,00 & 0 & 0,00 & \\
\hline Boninal & 0 & 0,00 & 0 & 0,00 & \\
\hline Bonito & 0 & 0,00 & 0 & 0,00 & \\
\hline Boquira & 0 & 0,00 & 0 & 0,00 & \\
\hline Botuporã & 0 & 0,00 & 0 & 0,00 & \\
\hline Brejões & 0 & 0,00 & 0 & 0,00 & \\
\hline Brejolândia & 0 & 0,00 & 0 & 0,00 & \\
\hline Brotas de Macaúbas & 0 & 0,00 & 0 & 0,00 & \\
\hline Brumado & 1 & 0,27 & 1 & 0,26 & $-3,55$ \\
\hline Buerarema & 0 & 0,00 & 0 & 0,00 & \\
\hline Buritirama & 1 & 0,74 & 0 & 0,00 & $-100,00$ \\
\hline
\end{tabular}


APÊNDICE A - TABELA DE INCIDÊNCIA MÉDIA ANUAL DE SÍFILIS CONGÊNITA

EM MENORES DE 1 ANO DE IDADE (POR 1.000 NV) SEGUNDO MUNICÍPIO

DE RESIDÊNCIA. ESTADO DA BAHIA - 2005-2008 E 2009-2012

(continuação)

\begin{tabular}{|c|c|c|c|c|c|}
\hline \multirow[b]{2}{*}{ Município de residência } & \multicolumn{2}{|r|}{ 2005-2008 } & \multicolumn{2}{|r|}{ 2009-2012 } & \multirow[b]{2}{*}{ Variação em \% } \\
\hline & no & $\begin{array}{c}\text { Incidência Média } \\
\text { Anual }\end{array}$ & no & $\begin{array}{c}\text { Incidência Média } \\
\text { Anual }\end{array}$ & \\
\hline Caatiba & 0 & 0,00 & 0 & 0,00 & \\
\hline Cabaceiras do Paraguaçu & 0 & 0,00 & 0 & 0,00 & \\
\hline Cachoeira & 0 & 0,00 & 2 & 1,20 & \\
\hline Caculé & 0 & 0,00 & 0 & 0,00 & \\
\hline Caém & 0 & 0,00 & 0 & 0,00 & \\
\hline Caetanos & 0 & 0,00 & 1 & 1,76 & \\
\hline Caetité & 3 & 0,82 & 1 & 0,35 & $-57,36$ \\
\hline Cafarnaum & 0 & 0,00 & 0 & 0,00 & \\
\hline Cairu & 0 & 0,00 & 0 & 0,00 & \\
\hline Caldeirão Grande & 0 & 0,00 & 1 & 1,32 & \\
\hline Camacan & 0 & 0,00 & 11 & 4,99 & \\
\hline Camaçari & 22 & 1,42 & 70 & 4,24 & 197,35 \\
\hline Camamu & 0 & 0,00 & 0 & 0,00 & \\
\hline Campo Alegre de Lourdes & 0 & 0,00 & 0 & 0,00 & \\
\hline Campo Formoso & 3 & 0,67 & 4 & 0,88 & 30,06 \\
\hline Canápolis & 0 & 0,00 & 0 & 0,00 & \\
\hline Canarana & 2 & 1,04 & 0 & 0,00 & $-100,00$ \\
\hline Canavieiras & 1 & 0,43 & 5 & 2,41 & 456,49 \\
\hline Candeal & 0 & 0,00 & 0 & 0,00 & \\
\hline Candeias & 12 & 2,50 & 32 & 6,86 & 174,84 \\
\hline Candiba & 0 & 0,00 & 0 & 0,00 & \\
\hline Cândido Sales & 1 & 0,50 & 4 & 2,52 & 404,73 \\
\hline Cansanção & 0 & 0,00 & 2 & 1,18 & \\
\hline Canudos & 1 & 1,08 & 1 & 1,06 & $-1,90$ \\
\hline Capela do Alto Alegre & 0 & 0,00 & 0 & 0,00 & \\
\hline Capim Grosso & 0 & 0,00 & 1 & 0,53 & \\
\hline Caraíbas & 0 & 0,00 & 0 & 0,00 & \\
\hline Caravelas & 2 & 1,58 & 3 & 2,45 & 54,65 \\
\hline Cardeal da Silva & 0 & 0,00 & 0 & 0,00 & \\
\hline
\end{tabular}


Revista Baiana de Saúde Pública
APÊNDICE A - TABELA DE INCIDÊNCIA MÉDIA ANUAL DE SÍFILIS CONGÊNITA

EM MENORES DE 1 ANO DE IDADE (POR 1.000 NV) SEGUNDO MUNICÍPIO

DE RESIDÊNCIA. ESTADO DA BAHIA - 2005-2008 E 2009-2012

(continuação)

\begin{tabular}{|c|c|c|c|c|c|}
\hline \multirow[b]{2}{*}{ Município de residência } & \multicolumn{2}{|c|}{ 2005-2008 } & \multicolumn{2}{|r|}{ 2009-2012 } & \multirow[b]{2}{*}{ Variação em \% } \\
\hline & no & $\begin{array}{c}\text { Incidência Média } \\
\text { Anual }\end{array}$ & no & $\begin{array}{c}\text { Incidência Média } \\
\text { Anual }\end{array}$ & \\
\hline Carinhanha & 0 & 0,00 & 0 & 0,00 & \\
\hline Casa Nova & 1 & 0,20 & 1 & 0,21 & 6,32 \\
\hline Castro Alves & 2 & 1,24 & 1 & 0,69 & $-44,49$ \\
\hline Catolândia & 0 & 0,00 & 0 & 0,00 & \\
\hline Catu & 4 & 1,32 & 2 & 0,72 & $-45,65$ \\
\hline Caturama & 0 & 0,00 & 0 & 0,00 & \\
\hline Central & 0 & 0,00 & 1 & 0,90 & \\
\hline Chorrochó & 0 & 0,00 & 0 & 0,00 & \\
\hline Cícero Dantas & 0 & 0,00 & 4 & 2,54 & \\
\hline Cipó & 0 & 0,00 & 1 & 0,85 & \\
\hline Coaraci & 2 & 1,24 & 3 & 2,35 & 90,47 \\
\hline Cocos & 0 & 0,00 & 0 & 0,00 & \\
\hline Conceição da Feira & 0 & 0,00 & 1 & 0,87 & \\
\hline Conceição do Almeida & 0 & 0,00 & 0 & 0,00 & \\
\hline Conceição do Coité & 2 & 0,44 & 2 & 0,53 & 20,70 \\
\hline Conceição do Jacuípe & 1 & 0,57 & 1 & 0,58 & 1,10 \\
\hline Conde & 0 & 0,00 & 4 & 2,81 & \\
\hline Condeúba & 0 & 0,00 & 0 & 0,00 & \\
\hline Contendas do Sincorá & 0 & 0,00 & 2 & 10,20 & \\
\hline Coração de Maria & 6 & 4,11 & 0 & 0,00 & $-100,00$ \\
\hline Cordeiros & 0 & 0,00 & 0 & 0,00 & \\
\hline Coribe & 0 & 0,00 & 1 & 1,32 & \\
\hline Coronel João Sá & 0 & 0,00 & 0 & 0,00 & \\
\hline Correntina & 0 & 0,00 & 0 & 0,00 & \\
\hline Cotegipe & 0 & 0,00 & 0 & 0,00 & \\
\hline Cravolândia & 0 & 0,00 & 0 & 0,00 & \\
\hline Crisópolis & 0 & 0,00 & 2 & 1,75 & \\
\hline Cristópolis & 0 & 0,00 & 1 & 1,35 & \\
\hline Cruz das Almas & 0 & 0,00 & 3 & 0,86 & \\
\hline
\end{tabular}


APÊNDICE A - TABELA DE INCIDÊNCIA MÉDIA ANUAL DE SÍFILIS CONGÊNITA

EM MENORES DE 1 ANO DE IDADE (POR 1.000 NV) SEGUNDO MUNICÍPIO

DE RESIDÊNCIA. ESTADO DA BAHIA - 2005-2008 E 2009-2012

(continuação)

\begin{tabular}{|c|c|c|c|c|c|}
\hline \multirow[b]{2}{*}{ Município de residência } & \multicolumn{2}{|c|}{ 2005-2008 } & \multicolumn{2}{|r|}{ 2009-2012 } & \multirow[b]{2}{*}{ Variação em \% } \\
\hline & no & $\begin{array}{c}\text { Incidência Média } \\
\text { Anual }\end{array}$ & no & $\begin{array}{c}\text { Incidência Média } \\
\text { Anual }\end{array}$ & \\
\hline Curaçá & 5 & 2,12 & 0 & 0,00 & $-100,00$ \\
\hline Dário Meira & 0 & 0,00 & 0 & 0,00 & \\
\hline Dias d'Ávila & 2 & 0,42 & 6 & 1,35 & 218,56 \\
\hline Dom Basílio & 0 & 0,00 & 0 & 0,00 & \\
\hline Dom Macedo Costa & 0 & 0,00 & 0 & 0,00 & \\
\hline Elísio Medrado & 0 & 0,00 & 1 & 2,61 & \\
\hline Encruzilhada & 1 & 0,61 & 1 & 0,72 & 18,19 \\
\hline Entre Rios & 4 & 1,41 & 4 & 1,67 & 18,46 \\
\hline Érico Cardoso & 0 & 0,00 & 0 & 0,00 & \\
\hline Esplanada & 0 & 0,00 & 2 & 0,96 & \\
\hline Euclides da Cunha & 0 & 0,00 & 1 & 0,30 & \\
\hline Eunápolis & 0 & 0,00 & 3 & 0,40 & \\
\hline Fátima & 0 & 0,00 & 0 & 0,00 & \\
\hline Feira da Mata & 0 & 0,00 & 0 & 0,00 & \\
\hline Feira de Santana & 92 & 2,73 & 91 & 2,43 & $-10,95$ \\
\hline Filadélfia & 0 & 0,00 & 0 & 0,00 & \\
\hline Firmino Alves & 0 & 0,00 & 0 & 0,00 & \\
\hline Floresta Azul & 0 & 0,00 & 0 & 0,00 & \\
\hline Formosa do Rio Preto & 2 & 1,27 & 0 & 0,00 & $-100,00$ \\
\hline Gandu & 0 & 0,00 & 2 & 0,94 & \\
\hline Gavião & 0 & 0,00 & 0 & 0,00 & \\
\hline Gentio do Ouro & 0 & 0,00 & 0 & 0,00 & \\
\hline Glória & 4 & 4,08 & 3 & 2,98 & $-26,86$ \\
\hline Gongogi & 0 & 0,00 & 0 & 0,00 & \\
\hline Governador Mangabeira & 0 & 0,00 & 2 & 1,76 & \\
\hline Guajeru & 0 & 0,00 & 0 & 0,00 & \\
\hline Guanambi & 3 & 0,64 & 4 & 0,85 & 34,41 \\
\hline Guaratinga & 1 & 0,74 & 1 & 0,76 & 3,13 \\
\hline Heliópolis & 0 & 0,00 & 0 & 0,00 & \\
\hline
\end{tabular}


Revista Baiana de Saúde Pública
APÊNDICE A - TABELA DE INCIDÊNCIA MÉDIA ANUAL DE SÍFILIS CONGÊNITA

EM MENORES DE 1 ANO DE IDADE (POR 1.000 NV) SEGUNDO MUNICÍPIO

DE RESIDÊNCIA. ESTADO DA BAHIA - 2005-2008 E 2009-2012

(continuação)

\begin{tabular}{|c|c|c|c|c|c|}
\hline \multirow[b]{2}{*}{ Município de residência } & \multicolumn{2}{|r|}{ 2005-2008 } & \multicolumn{2}{|r|}{ 2009-2012 } & \multirow[b]{2}{*}{ Variação em \% } \\
\hline & no & $\begin{array}{c}\text { Incidência Média } \\
\text { Anual }\end{array}$ & no & $\begin{array}{c}\text { Incidência Média } \\
\text { Anual }\end{array}$ & \\
\hline laçu & 0 & 0,00 & 1 & 0,61 & \\
\hline Ibiassucê & 0 & 0,00 & 0 & 0,00 & \\
\hline Ibicaraí & 1 & 0,57 & 3 & 2,14 & 275,64 \\
\hline Ibicoara & 0 & 0,00 & 2 & 1,47 & \\
\hline Ibicuí & 0 & 0,00 & 0 & 0,00 & \\
\hline Ibipeba & 0 & 0,00 & 0 & 0,00 & \\
\hline Ibipitanga & 0 & 0,00 & 1 & 1,55 & \\
\hline Ibiquera & 0 & 0,00 & 0 & 0,00 & \\
\hline Ibirapitanga & 0 & 0,00 & 0 & 0,00 & \\
\hline Ibirapuã & 0 & 0,00 & 0 & 0,00 & \\
\hline Ibirataia & 2 & 1,21 & 0 & 0,00 & $-100,00$ \\
\hline Ibitiara & 0 & 0,00 & 0 & 0,00 & \\
\hline Ibititá & 0 & 0,00 & 0 & 0,00 & \\
\hline Ibotirama & 0 & 0,00 & 1 & 0,57 & \\
\hline Ichu & 0 & 0,00 & 1 & 3,58 & \\
\hline Igaporã & 1 & 1,42 & 0 & 0,00 & $-100,00$ \\
\hline Igrapiúna & 1 & 1,21 & 2 & 2,63 & 117,35 \\
\hline Iguaí & 0 & 0,00 & 0 & 0,00 & \\
\hline Ilhéus & 4 & 0,33 & 95 & 8,39 & 2447,24 \\
\hline Inhambupe & 1 & 0,40 & 3 & 1,42 & 258,55 \\
\hline Ipecaetá & 0 & 0,00 & 1 & 1,21 & \\
\hline Ipiaú & 2 & 0,71 & 3 & 1,04 & 46,84 \\
\hline Ipirá & 1 & 0,25 & 1 & 0,27 & 7,45 \\
\hline Ipupiara & 0 & 0,00 & 0 & 0,00 & \\
\hline Irajuba & 0 & 0,00 & 0 & 0,00 & \\
\hline Iramaia & 0 & 0,00 & 0 & 0,00 & \\
\hline Iraquara & 0 & 0,00 & 0 & 0,00 & \\
\hline Irará & 2 & 1,19 & 0 & 0,00 & $-100,00$ \\
\hline Irecê & 1 & 0,20 & 2 & 0,43 & 110,25 \\
\hline
\end{tabular}


APÊNDICE A - TABELA DE INCIDÊNCIA MÉDIA ANUAL DE SÍFILIS CONGÊNITA

EM MENORES DE 1 ANO DE IDADE (POR 1.000 NV) SEGUNDO MUNICÍPIO

DE RESIDÊNCIA. ESTADO DA BAHIA - 2005-2008 E 2009-2012

(continuação)

\begin{tabular}{|c|c|c|c|c|c|}
\hline \multirow[b]{2}{*}{ Município de residência } & \multicolumn{2}{|c|}{ 2005-2008 } & \multicolumn{2}{|r|}{ 2009-2012 } & \multirow[b]{2}{*}{ Variação em \% } \\
\hline & no & $\begin{array}{c}\text { Incidência Média } \\
\text { Anual }\end{array}$ & no & $\begin{array}{c}\text { Incidência Média } \\
\text { Anual }\end{array}$ & \\
\hline Itabela & 1 & 0,39 & 8 & 3,53 & 793,08 \\
\hline Itaberaba & 2 & 0,45 & 2 & 0,52 & 14,90 \\
\hline Itabuna & 17 & 1,23 & 11 & 0,82 & $-33,38$ \\
\hline Itacaré & 0 & 0,00 & 1 & 0,74 & \\
\hline Itaeté & 0 & 0,00 & 0 & 0,00 & \\
\hline Itagi & 0 & 0,00 & 1 & 1,18 & \\
\hline Itagibá & 2 & 1,96 & 0 & 0,00 & $-100,00$ \\
\hline Itagimirim & 1 & 1,85 & 0 & 0,00 & $-100,00$ \\
\hline Itaguaçu da Bahia & 2 & 2,21 & 1 & 1,35 & $-38,87$ \\
\hline Itaju do Colônia & 0 & 0,00 & 1 & 3,15 & \\
\hline Itajuípe & 1 & 0,63 & 0 & 0,00 & $-100,00$ \\
\hline Itamaraju & 12 & 2,32 & 4 & 0,82 & $-64,72$ \\
\hline Itamari & 0 & 0,00 & 0 & 0,00 & \\
\hline Itambé & 2 & 1,34 & 11 & 7,65 & 472,20 \\
\hline Itanagra & 0 & 0,00 & 0 & 0,00 & \\
\hline Itanhém & 0 & 0,00 & 1 & 1,01 & \\
\hline Itaparica & 1 & 0,82 & 2 & 1,86 & 127,35 \\
\hline Itapé & 0 & 0,00 & 0 & 0,00 & \\
\hline Itapebi & 0 & 0,00 & 0 & 0,00 & \\
\hline Itapetinga & 1 & 0,21 & 3 & 0,65 & 210,16 \\
\hline Itapicuru & 0 & 0,00 & 2 & 1,18 & \\
\hline Itapitanga & 0 & 0,00 & 1 & 2,60 & \\
\hline Itaquara & 0 & 0,00 & 0 & 0,00 & \\
\hline Itarantim & 0 & 0,00 & 0 & 0,00 & \\
\hline Itatim & 0 & 0,00 & 2 & 2,30 & \\
\hline Itiruçu & 0 & 0,00 & 0 & 0,00 & \\
\hline Itiúba & 0 & 0,00 & 0 & 0,00 & \\
\hline Itororó & 0 & 0,00 & 2 & 1,67 & \\
\hline Ituaçu & 0 & 0,00 & 0 & 0,00 & \\
\hline
\end{tabular}


Revista Baiana de Saúde Pública
APÊNDICE A - TABELA DE INCIDÊNCIA MÉDIA ANUAL DE SÍFILIS CONGÊNITA

EM MENORES DE 1 ANO DE IDADE (POR 1.000 NV) SEGUNDO MUNICÍPIO

DE RESIDÊNCIA. ESTADO DA BAHIA - 2005-2008 E 2009-2012

(continuação)

\begin{tabular}{|c|c|c|c|c|c|}
\hline \multirow[b]{2}{*}{ Município de residência } & \multicolumn{2}{|r|}{ 2005-2008 } & \multicolumn{2}{|r|}{ 2009-2012 } & \multirow[b]{2}{*}{ Variação em \% } \\
\hline & no & $\begin{array}{c}\text { Incidência Média } \\
\text { Anual }\end{array}$ & no & $\begin{array}{c}\text { Incidência Média } \\
\text { Anual }\end{array}$ & \\
\hline Ituberá & 2 & 0,87 & 0 & 0,00 & $-100,00$ \\
\hline luiú & 0 & 0,00 & 0 & 0,00 & \\
\hline Jaborandi & 0 & 0,00 & 0 & 0,00 & \\
\hline Jacaraci & 0 & 0,00 & 0 & 0,00 & \\
\hline Jacobina & 5 & 0,91 & 1 & 0,19 & $-78,62$ \\
\hline Jaguaquara & 0 & 0,00 & 0 & 0,00 & \\
\hline Jaguarari & 0 & 0,00 & 0 & 0,00 & \\
\hline Jaguaripe & 0 & 0,00 & 0 & 0,00 & \\
\hline Jandaíra & 0 & 0,00 & 0 & 0,00 & \\
\hline Jequié & 3 & 0,29 & 23 & 2,34 & 701,85 \\
\hline Jeremoabo & 0 & 0,00 & 2 & 0,87 & \\
\hline Jiquiriçá & 0 & 0,00 & 1 & 1,47 & \\
\hline Jitaúna & 0 & 0,00 & 0 & 0,00 & \\
\hline João Dourado & 0 & 0,00 & 0 & 0,00 & \\
\hline Juazeiro & 29 & 1,77 & 36 & 2,27 & 28,60 \\
\hline Jucuruçu & 0 & 0,00 & 0 & 0,00 & \\
\hline Jussara & 0 & 0,00 & 0 & 0,00 & \\
\hline Jussari & 0 & 0,00 & 0 & 0,00 & \\
\hline Jussiape & 0 & 0,00 & 0 & 0,00 & \\
\hline Lafaiete Coutinho & 0 & 0,00 & 0 & 0,00 & \\
\hline Lagoa Real & 0 & 0,00 & 0 & 0,00 & \\
\hline Laje & 0 & 0,00 & 1 & 0,73 & \\
\hline Lajedão & 0 & 0,00 & 0 & 0,00 & \\
\hline Lajedinho & 1 & 3,76 & 0 & 0,00 & $-100,00$ \\
\hline Lajedo do Tabocal & 0 & 0,00 & 0 & 0,00 & \\
\hline Lamarão & 1 & 4,42 & 0 & 0,00 & $-100,00$ \\
\hline Lapão & 1 & 0,47 & 0 & 0,00 & $-100,00$ \\
\hline Lauro de Freitas & 14 & 1,32 & 31 & 2,63 & 99,62 \\
\hline Lençóis & 0 & 0,00 & 0 & 0,00 & \\
\hline
\end{tabular}


APÊNDICE A - TABELA DE INCIDÊNCIA MÉDIA ANUAL DE SÍFILIS CONGÊNITA

EM MENORES DE 1 ANO DE IDADE (POR 1.000 NV) SEGUNDO MUNICÍPIO

DE RESIDÊNCIA. ESTADO DA BAHIA - 2005-2008 E 2009-2012

(continuação)

\begin{tabular}{|c|c|c|c|c|c|}
\hline \multirow[b]{2}{*}{ Município de residência } & \multicolumn{2}{|c|}{ 2005-2008 } & \multicolumn{2}{|r|}{ 2009-2012 } & \multirow[b]{2}{*}{ Variação em \% } \\
\hline & $\mathrm{n} \underline{\mathbf{o}}$ & $\begin{array}{c}\text { Incidência Média } \\
\text { Anual }\end{array}$ & no & $\begin{array}{c}\text { Incidência Média } \\
\text { Anual }\end{array}$ & \\
\hline Licínio de Almeida & 0 & 0,00 & 0 & 0,00 & \\
\hline Livramento do Brumado & 0 & 0,00 & 0 & 0,00 & \\
\hline Luís Eduardo Magalhães & 4 & 0,98 & 10 & 1,83 & 87,22 \\
\hline Macajuba & 1 & 1,15 & 0 & 0,00 & $-100,00$ \\
\hline Macarani & 0 & 0,00 & 0 & 0,00 & \\
\hline Macaúbas & 0 & 0,00 & 1 & 0,43 & \\
\hline Macururé & 1 & 2,08 & 0 & 0,00 & $-100,00$ \\
\hline Madre de Deus & 1 & 0,84 & 1 & 0,85 & 1,45 \\
\hline Maetinga & 0 & 0,00 & 0 & 0,00 & \\
\hline Maiquinique & 0 & 0,00 & 0 & 0,00 & \\
\hline Mairi & 3 & 2,71 & 0 & 0,00 & $-100,00$ \\
\hline Malhada & 0 & 0,00 & 1 & 0,93 & \\
\hline Malhada de Pedras & 0 & 0,00 & 0 & 0,00 & \\
\hline Manoel Vitorino & 0 & 0,00 & 0 & 0,00 & \\
\hline Mansidão & 0 & 0,00 & 0 & 0,00 & \\
\hline Maracás & 0 & 0,00 & 0 & 0,00 & \\
\hline Maragogipe & 0 & 0,00 & 2 & 0,87 & \\
\hline Maraú & 0 & 0,00 & 0 & 0,00 & \\
\hline Marcionílio Souza & 0 & 0,00 & 0 & 0,00 & \\
\hline Mascote & 1 & 1,04 & 0 & 0,00 & $-100,00$ \\
\hline Mata de São João & 0 & 0,00 & 6 & 2,00 & \\
\hline Matina & 0 & 0,00 & 0 & 0,00 & \\
\hline Medeiros Neto & 0 & 0,00 & 4 & 3,01 & \\
\hline Miguel Calmon & 0 & 0,00 & 0 & 0,00 & \\
\hline Milagres & 0 & 0,00 & 0 & 0,00 & \\
\hline Mirangaba & 0 & 0,00 & 1 & 1,16 & \\
\hline Mirante & 1 & 2,05 & 0 & 0,00 & $-100,00$ \\
\hline Monte Santo & 1 & 0,29 & 0 & 0,00 & $-100,00$ \\
\hline Morpará & 0 & 0,00 & 0 & 0,00 & \\
\hline
\end{tabular}


Revista Baiana de Saúde Pública
APÊNDICE A - TABELA DE INCIDÊNCIA MÉDIA ANUAL DE SÍFILIS CONGÊNITA

EM MENORES DE 1 ANO DE IDADE (POR 1.000 NV) SEGUNDO MUNICÍPIO

DE RESIDÊNCIA. ESTADO DA BAHIA - 2005-2008 E 2009-2012

(continuação)

\begin{tabular}{|c|c|c|c|c|c|}
\hline \multirow[b]{2}{*}{ Município de residência } & \multicolumn{2}{|r|}{ 2005-2008 } & \multicolumn{2}{|r|}{ 2009-2012 } & \multirow[b]{2}{*}{ Variação em \% } \\
\hline & no & $\begin{array}{c}\text { Incidência Média } \\
\text { Anual }\end{array}$ & no & $\begin{array}{c}\text { Incidência Média } \\
\text { Anual }\end{array}$ & \\
\hline Morro do Chapéu & 0 & 0,00 & 3 & 1,18 & \\
\hline Mortugaba & 0 & 0,00 & 0 & 0,00 & \\
\hline Mucugê & 0 & 0,00 & 0 & 0,00 & \\
\hline Mucuri & 0 & 0,00 & 1 & 0,35 & \\
\hline Mulungu do Morro & 0 & 0,00 & 0 & 0,00 & \\
\hline Mundo Novo & 0 & 0,00 & 0 & 0,00 & \\
\hline Muniz Ferreira & 0 & 0,00 & 1 & 2,58 & \\
\hline Muquém de São Francisco & 0 & 0,00 & 0 & 0,00 & \\
\hline Muritiba & 0 & 0,00 & 2 & 1,38 & \\
\hline Mutuípe & 0 & 0,00 & 2 & 1,76 & \\
\hline Nazaré & 0 & 0,00 & 4 & 2,43 & \\
\hline Nilo Peçanha & 0 & 0,00 & 0 & 0,00 & \\
\hline Nordestina & 0 & 0,00 & 0 & 0,00 & \\
\hline Nova Canaã & 0 & 0,00 & 2 & 2,50 & \\
\hline Nova Fátima & 0 & 0,00 & 0 & 0,00 & \\
\hline Nova Ibiá & 0 & 0,00 & 0 & 0,00 & \\
\hline Nova Itarana & 0 & 0,00 & 2 & 4,18 & \\
\hline Nova Redenção & 2 & 3,79 & 0 & 0,00 & $-100,00$ \\
\hline Nova Soure & 0 & 0,00 & 0 & 0,00 & \\
\hline Nova Viçosa & 2 & 0,76 & 4 & 1,46 & 91,46 \\
\hline Novo Horizonte & 0 & 0,00 & 0 & 0,00 & \\
\hline Novo Triunfo & 0 & 0,00 & 0 & 0,00 & \\
\hline Olindina & 0 & 0,00 & 0 & 0,00 & \\
\hline Oliveira dos Brejinhos & 0 & 0,00 & 0 & 0,00 & \\
\hline Ouriçangas & 0 & 0,00 & 0 & 0,00 & \\
\hline Ourolândia & 1 & 0,68 & 0 & 0,00 & $-100,00$ \\
\hline Palmas de Monte Alto & 1 & 0,82 & 0 & 0,00 & $-100,00$ \\
\hline Palmeiras & 0 & 0,00 & 0 & 0,00 & \\
\hline Paramirim & 0 & 0,00 & 0 & 0,00 & \\
\hline
\end{tabular}


APÊNDICE A - TABELA DE INCIDÊNCIA MÉDIA ANUAL DE SÍFILIS CONGÊNITA

EM MENORES DE 1 ANO DE IDADE (POR 1.000 NV) SEGUNDO MUNICÍPIO

DE RESIDÊNCIA. ESTADO DA BAHIA - 2005-2008 E 2009-2012

(continuação)

\begin{tabular}{|c|c|c|c|c|c|}
\hline \multirow[b]{2}{*}{ Município de residência } & \multicolumn{2}{|r|}{ 2005-2008 } & \multicolumn{2}{|r|}{ 2009-2012 } & \multirow[b]{2}{*}{ Variação em \% } \\
\hline & no & $\begin{array}{c}\text { Incidência Média } \\
\text { Anual }\end{array}$ & no & $\begin{array}{c}\text { Incidência Média } \\
\text { Anual }\end{array}$ & \\
\hline Paratinga & 0 & 0,00 & 1 & 0,53 & \\
\hline Paripiranga & 0 & 0,00 & 2 & 1,34 & \\
\hline Pau Brasil & 1 & 1,09 & 0 & 0,00 & $-100,00$ \\
\hline Paulo Afonso & 13 & 1,75 & 11 & 1,45 & $-17,23$ \\
\hline Pé de Serra & 0 & 0,00 & 0 & 0,00 & \\
\hline Pedrão & 0 & 0,00 & 0 & 0,00 & \\
\hline Pedro Alexandre & 0 & 0,00 & 0 & 0,00 & \\
\hline Piatã & 0 & 0,00 & 0 & 0,00 & \\
\hline Pilão Arcado & 0 & 0,00 & 0 & 0,00 & \\
\hline Pindaí & 0 & 0,00 & 0 & 0,00 & \\
\hline Pindobaçu & 0 & 0,00 & 0 & 0,00 & \\
\hline Pintadas & 0 & 0,00 & 0 & 0,00 & \\
\hline Piraí do Norte & 0 & 0,00 & 0 & 0,00 & \\
\hline Piripá & 1 & 2,04 & 0 & 0,00 & $-100,00$ \\
\hline Piritiba & 0 & 0,00 & 0 & 0,00 & \\
\hline Planaltino & 0 & 0,00 & 0 & 0,00 & \\
\hline Planalto & 2 & 1,16 & 0 & 0,00 & $-100,00$ \\
\hline Poções & 2 & 0,62 & 3 & 1,09 & 75,31 \\
\hline Pojuca & 0 & 0,00 & 1 & 0,43 & \\
\hline Ponto Novo & 0 & 0,00 & 1 & 0,94 & \\
\hline Porto Seguro & 89 & 8,81 & 40 & 4,13 & $-53,13$ \\
\hline Potiraguá & 0 & 0,00 & 2 & 3,18 & \\
\hline Prado & 2 & 1,19 & 2 & 1,21 & 0,96 \\
\hline Presidente Dutra & 0 & 0,00 & 0 & 0,00 & \\
\hline Presidente Jânio Quadros & 0 & 0,00 & 1 & 1,89 & \\
\hline Presidente Tancredo Neves & 0 & 0,00 & 1 & 0,59 & \\
\hline Queimadas & 0 & 0,00 & 1 & 0,72 & \\
\hline Quijingue & 0 & 0,00 & 0 & 0,00 & \\
\hline Quixabeira & 0 & 0,00 & 0 & 0,00 & \\
\hline
\end{tabular}


Revista Baiana de Saúde Pública
APÊNDICE A - TABELA DE INCIDÊNCIA MÉDIA ANUAL DE SÍFILIS CONGÊNITA

EM MENORES DE 1 ANO DE IDADE (POR 1.000 NV) SEGUNDO MUNICÍPIO

DE RESIDÊNCIA. ESTADO DA BAHIA - 2005-2008 E 2009-2012

(continuação)

\begin{tabular}{|c|c|c|c|c|c|}
\hline \multirow[b]{2}{*}{ Município de residência } & \multicolumn{2}{|c|}{ 2005-2008 } & \multicolumn{2}{|r|}{ 2009-2012 } & \multirow[b]{2}{*}{ Variação em \% } \\
\hline & no & $\begin{array}{c}\text { Incidência Média } \\
\text { Anual }\end{array}$ & no & $\begin{array}{c}\text { Incidência Média } \\
\text { Anual }\end{array}$ & \\
\hline Rafael Jambeiro & 0 & 0,00 & 2 & 1,69 & \\
\hline Remanso & 6 & 1,87 & 1 & 0,33 & $-82,50$ \\
\hline Retirolândia & 0 & 0,00 & 1 & 1,14 & \\
\hline Riachão das Neves & 0 & 0,00 & 0 & 0,00 & \\
\hline Riachão do Jacuípe & 0 & 0,00 & 1 & 0,62 & \\
\hline Riacho de Santana & 0 & 0,00 & 0 & 0,00 & \\
\hline Ribeira do Amparo & 0 & 0,00 & 0 & 0,00 & \\
\hline Ribeira do Pombal & 0 & 0,00 & 1 & 0,31 & \\
\hline Ribeirão do Largo & 0 & 0,00 & 0 & 0,00 & \\
\hline Rio de Contas & 0 & 0,00 & 0 & 0,00 & \\
\hline Rio do Antônio & 0 & 0,00 & 0 & 0,00 & \\
\hline Rio do Pires & 0 & 0,00 & 0 & 0,00 & \\
\hline Rio Real & 2 & 0,73 & 11 & 4,52 & 518,64 \\
\hline Rodelas & 1 & 1,78 & 0 & 0,00 & $-100,00$ \\
\hline Ruy Barbosa & 4 & 1,93 & 4 & 2,14 & 10,88 \\
\hline Salinas da Margarida & 0 & 0,00 & 0 & 0,00 & \\
\hline Salvador & 371 & 2,48 & 607 & 4,09 & 65,37 \\
\hline Santa Bárbara & 1 & 0,83 & 1 & 0,76 & $-8,33$ \\
\hline Santa Brígida & 0 & 0,00 & 0 & 0,00 & \\
\hline Santa Cruz Cabrália & 3 & 1,53 & 5 & 2,94 & 91,92 \\
\hline Santa Cruz da Vitória & 1 & 3,34 & 0 & 0,00 & $-100,00$ \\
\hline Santa Inês & 0 & 0,00 & 0 & 0,00 & \\
\hline Santa Luzia & 1 & 1,29 & 0 & 0,00 & $-100,00$ \\
\hline Santa Maria da Vitória & 1 & 0,44 & 1 & 0,42 & $-3,69$ \\
\hline Santa Rita de Cássia & 1 & 0,69 & 1 & 0,57 & $-18,07$ \\
\hline Santa Teresinha & 0 & 0,00 & 2 & 3,30 & \\
\hline Santaluz & 0 & 0,00 & 0 & 0,00 & \\
\hline Santana & 0 & 0,00 & 1 & 0,70 & \\
\hline Santanópolis & 0 & 0,00 & 0 & 0,00 & \\
\hline
\end{tabular}


APÊNDICE A - TABELA DE INCIDÊNCIA MÉDIA ANUAL DE SÍFILIS CONGÊNITA

EM MENORES DE 1 ANO DE IDADE (POR 1.000 NV) SEGUNDO MUNICÍPIO

DE RESIDÊNCIA. ESTADO DA BAHIA - 2005-2008 E 2009-2012

(continuação)

\begin{tabular}{|c|c|c|c|c|c|}
\hline \multirow[b]{2}{*}{ Município de residência } & \multicolumn{2}{|r|}{ 2005-2008 } & \multicolumn{2}{|r|}{ 2009-2012 } & \multirow[b]{2}{*}{ Variação em \% } \\
\hline & no & $\begin{array}{c}\text { Incidência Média } \\
\text { Anual }\end{array}$ & no & $\begin{array}{c}\text { Incidência Média } \\
\text { Anual }\end{array}$ & \\
\hline Santo Amaro & 3 & 0,84 & 5 & 1,59 & 89,71 \\
\hline Santo Antônio de Jesus & 6 & 1,09 & 12 & 2,06 & 89,64 \\
\hline Santo Estêvão & 2 & 0,69 & 2 & 0,65 & $-5,56$ \\
\hline São Desidério & 0 & 0,00 & 2 & 1,02 & \\
\hline São Domingos & 0 & 0,00 & 0 & 0,00 & \\
\hline São Felipe & 0 & 0,00 & 0 & 0,00 & \\
\hline São Félix & 0 & 0,00 & 0 & 0,00 & \\
\hline São Félix do Coribe & 1 & 1,09 & 0 & 0,00 & $-100,00$ \\
\hline São Francisco do Conde & 2 & 1,05 & 4 & 1,59 & 51,67 \\
\hline São Gabriel & 0 & 0,00 & 0 & 0,00 & \\
\hline São Gonçalo dos Campos & 0 & 0,00 & 0 & 0,00 & \\
\hline São José da Vitória & 0 & 0,00 & 1 & 2,45 & \\
\hline São José do Jacuípe & 0 & 0,00 & 1 & 1,90 & \\
\hline São Miguel das Matas & 1 & 1,55 & 1 & 1,81 & 17,21 \\
\hline São Sebastião do Passé & 3 & 1,32 & 6 & 2,50 & 88,99 \\
\hline Sapeaçu & 0 & 0,00 & 0 & 0,00 & \\
\hline Sátiro Dias & 0 & 0,00 & 0 & 0,00 & \\
\hline Saubara & 1 & 1,78 & 0 & 0,00 & $-100,00$ \\
\hline Saúde & 0 & 0,00 & 0 & 0,00 & \\
\hline Seabra & 1 & 0,34 & 0 & 0,00 & $-100,00$ \\
\hline Sebastião Laranjeiras & 0 & 0,00 & 0 & 0,00 & \\
\hline Senhor do Bonfim & 4 & 0,79 & 11 & 2,37 & 198,66 \\
\hline Sento Sé & 1 & 0,37 & 6 & 2,60 & 611,27 \\
\hline Serra do Ramalho & 0 & 0,00 & 0 & 0,00 & \\
\hline Serra Dourada & 0 & 0,00 & 0 & 0,00 & \\
\hline Serra Preta & 0 & 0,00 & 4 & 4,68 & \\
\hline Serrinha & 2 & 0,39 & 2 & 0,39 & $-0,91$ \\
\hline Serrolândia & 0 & 0,00 & 0 & 0,00 & \\
\hline Simões Filho & 12 & 1,41 & 24 & 3,03 & 114,57 \\
\hline
\end{tabular}


Revista Baiana de Saúde Pública
APÊNDICE A - TABELA DE INCIDÊNCIA MÉDIA ANUAL DE SÍFILIS CONGÊNITA

EM MENORES DE 1 ANO DE IDADE (POR 1.000 NV) SEGUNDO MUNICÍPIO

DE RESIDÊNCIA. ESTADO DA BAHIA - 2005-2008 E 2009-2012

(continuação)

\begin{tabular}{|c|c|c|c|c|c|}
\hline \multirow[b]{2}{*}{ Município de residência } & \multicolumn{2}{|c|}{ 2005-2008 } & \multicolumn{2}{|r|}{ 2009-2012 } & \multirow[b]{2}{*}{ Variação em \% } \\
\hline & no & $\begin{array}{c}\text { Incidência Média } \\
\text { Anual }\end{array}$ & no & $\begin{array}{c}\text { Incidência Média } \\
\text { Anual }\end{array}$ & \\
\hline Sítio do Mato & 0 & 0,00 & 0 & 0,00 & \\
\hline Sítio do Quinto & 0 & 0,00 & 0 & 0,00 & \\
\hline Sobradinho & 4 & 2,42 & 9 & 5,67 & 133,78 \\
\hline Souto Soares & 0 & 0,00 & 0 & 0,00 & \\
\hline Tabocas do Brejo Velho & 0 & 0,00 & 0 & 0,00 & \\
\hline Tanhaçu & 0 & 0,00 & 2 & 1,99 & \\
\hline Tanque Novo & 0 & 0,00 & 0 & 0,00 & \\
\hline Tanquinho & 1 & 2,26 & 1 & 2,65 & 16,93 \\
\hline Taperoá & 0 & 0,00 & 0 & 0,00 & \\
\hline Tapiramutá & 0 & 0,00 & 3 & 2,91 & \\
\hline Teixeira de Freitas & 0 & 0,00 & 81 & 7,77 & \\
\hline Teodoro Sampaio & 0 & 0,00 & 1 & 2,81 & \\
\hline Teofilândia & 1 & 1,35 & 1 & 0,72 & $-46,39$ \\
\hline Teolândia & 0 & 0,00 & 0 & 0,00 & \\
\hline Terra Nova & 1 & 1,63 & 4 & 5,87 & 260,65 \\
\hline Tremedal & 0 & 0,00 & 0 & 0,00 & \\
\hline Tucano & 1 & 0,34 & 1 & 0,37 & 9,53 \\
\hline Uauá & 0 & 0,00 & 0 & 0,00 & \\
\hline Ubaíra & 0 & 0,00 & 0 & 0,00 & \\
\hline Ubaitaba & 1 & 0,62 & 2 & 1,39 & 124,93 \\
\hline Ubatã & 0 & 0,00 & 1 & 0,80 & \\
\hline Uibaí & 0 & 0,00 & 0 & 0,00 & \\
\hline Umburanas & 0 & 0,00 & 0 & 0,00 & \\
\hline Una & 4 & 2,58 & 5 & 3,83 & 48,56 \\
\hline Urandi & 0 & 0,00 & 0 & 0,00 & \\
\hline Uruçuca & 0 & 0,00 & 4 & 2,78 & \\
\hline Utinga & 0 & 0,00 & 0 & 0,00 & \\
\hline Valença & 0 & 0,00 & 0 & 0,00 & \\
\hline Valente & 0 & 0,00 & 0 & 0,00 & \\
\hline
\end{tabular}


APÊNDICE A - TABELA DE INCIDÊNCIA MÉDIA ANUAL DE SÍFILIS CONGÊNITA

EM MENORES DE 1 ANO DE IDADE (POR 1.000 NV) SEGUNDO MUNICÍPIO

DE RESIDÊNCIA. ESTADO DA BAHIA - 2005-2008 E 2009-2012

(conclusão)

\begin{tabular}{|c|c|c|c|c|c|}
\hline \multirow[b]{2}{*}{ Município de residência } & \multicolumn{2}{|r|}{ 2005-2008 } & \multicolumn{2}{|r|}{ 2009-2012 } & \multirow[b]{2}{*}{ Variação em \% } \\
\hline & no & $\begin{array}{c}\text { Incidência Média } \\
\text { Anual }\end{array}$ & no & $\begin{array}{c}\text { Incidência Média } \\
\text { Anual }\end{array}$ & \\
\hline Várzea da Roça & 0 & 0,00 & 0 & 0,00 & \\
\hline Várzea do Poço & 0 & 0,00 & 0 & 0,00 & \\
\hline Várzea Nova & 0 & 0,00 & 1 & 1,37 & \\
\hline Varzedo & 0 & 0,00 & 0 & 0,00 & \\
\hline Vera Cruz & 6 & 2,55 & 6 & 2,74 & 7,31 \\
\hline Vereda & 0 & 0,00 & 0 & 0,00 & \\
\hline Vitória da Conquista & 86 & 3,97 & 75 & 3,53 & $-11,20$ \\
\hline Wagner & 0 & 0,00 & 0 & 0,00 & \\
\hline Wanderley & 2 & 2,19 & 0 & 0,00 & $-100,00$ \\
\hline Wenceslau Guimarães & 0 & 0,00 & 1 & 0,65 & \\
\hline Xique-Xique & 0 & 0,00 & 0 & 0,00 & \\
\hline Total & 1007 & 1,13 & 1648 & 1,92 & 70,94 \\
\hline
\end{tabular}

Fonte: Elaboração própria com base em dados coletados do Sinan Windows, Sinan NET, SIM, Sinasc. 